\title{
Simulation of Cyclic Transformations in the Intercritical Range of a 5Mn Steel
}

\section{P.I. Sarafoglou, M.I.T. Tzini and G.N. Haidemenopoulos ${ }^{\star}$}

Department of Mechanical Engineering, University of Thessaly, Pedion Areos, 38500 Volos, Greece

\begin{abstract}
Partial cyclic phase transformations $\alpha \rightarrow \gamma$ and $\gamma \rightarrow \alpha$ triggered by temperature cycling in the intercritical range $(\alpha+\gamma)$ have been simulated in a medium-Mn steel with composition Fe- $0.2 \mathrm{C}-5 \mathrm{Mn}$. Additional simulations have been performed in Fe-0.2C-0.2Mn and Fe-0.2C steels for comparison. The computational kinetics software DICTRA has been employed for the simulations. All simulations were carried out under local equilibrium conditions. A specially-designed thermal cycle was considered. The position and the velocity of the austenite-ferrite interface were monitored during temperature cycling. Cyclic behavior is characterized by hysteresis loop formation. No loop formation was observed for the plain carbon steel. The inverse transformation, where the interface proceeds in a direction opposite to the temperature change has been identified for the Fe- $0.2 \mathrm{C}-5 \mathrm{Mn}$ steel. The duration of the inverse transformation stage is larger at the minimum temperature of the cycle while the phase fraction formed during the inverse transformation is larger at the maximum temperature of the cycle. When the cyclic transformation takes place at a time before the final phase equilibrium in the isothermal curve, the transformation is characterized as inverse during the whole cooling part of the cycle. A stagnant stage where the transformation is very sluggish was observed during the cyclic transformations for the steels investigated. The study of cyclic transformations provides insight into the kinetics of phase transformations in medium-Mn steels.
\end{abstract}

\section{Introduction}

Medium-Mn steels constitute the core of the $3^{\text {rd }}$ generation advanced high-strength steels. These steels are under development as a substitute to 1st (low alloy) and 2nd generation (high-Mn) steels, aiming at improved combinations of strength and ductility [1-4]. In medium-Mn steels, the manganese content is in the range between 3 and 12 pct and the microstructure consists of an ultrafine ferriteaustenite mixture. The transformation-induced plasticity (TRIP) of the retained austenite is responsible for the enhanced formability in these steels. Austenite stability is the key factor controlling TRIP interactions and several processing routes have been developed in order to stabilize the austenite such as the quench and partitioning (Q\&P) process [5,6] and intercritical annealing [7-12]. In the second process, austenite is stabilized by carbon and manganese partitioning. The retained austenite fraction and stability depend, therefore, on the intercritical annealing temperature and time. Understanding the kinetics of phase transformations during intercritical annealing is a prerequisite towards designing steel compositions and annealing treatments for austenite stabilization. The study of cyclic $\alpha \rightarrow \gamma$ and $\gamma \rightarrow \alpha$ transformations in the intercritical range has been proposed as a means to investigate the growth kinetics in low-Mn and low-C FeMn-C alloys $[13,14]$. There are certain advantages in studying cyclic phase transformations. The first is that growth can be isolated and studied exclusively without the intervention of nucleation. The second stems from the fact that $\alpha \rightarrow \gamma$ and $\gamma \rightarrow \alpha$ transformations proceed at different rates isothermally, and, therefore, cyclic transformations can provide insight in the growth kinetics. In the present work, the cyclic transformation approach was applied in medium-Mn steels. The aim of the work is to describe growth during $\alpha \rightarrow \gamma$ and $\gamma \rightarrow a$ transformations by monitoring the position and the velocity of the $\alpha / \gamma$ interface with temperature and time and to quantify specific stages of the transformation such as the "stagnant" and "inverse" stages described in [14]. Solute partitioning between austenite and ferrite during cyclic transformations is under investigation and has not been considered in detail in this work.

\section{Methodology}

The steel under investigation was a medium-Mn, Fe-0.2C-5Mn. A lean- $\mathrm{Mn}$ Fe- $0.2 \mathrm{C}-0.2 \mathrm{Mn}$ and a plain carbon Fe- $0.2 \mathrm{C}$ steel were also considered as reference materials (compositions in mass\%).Critical $\mathrm{A} 1$ and $\mathrm{A} 3$ temperatures were identified by constructing the respective isopleth sections at constant $\mathrm{Mn}$ compositions, as shown in Figure 1. The cyclic thermal treatment considered is depicted in Figure 2. The cycle starts with an isothermal holding at $\mathrm{T}_{\text {is }}$, followed by temperature cycling between $\mathrm{T}_{\text {max }}$ and $\mathrm{T}_{\text {min }}$.

Two cases were considered. The first case is concerned with the $a \rightarrow \gamma$ transformation, corresponding to the intercritical annealing of supersaturated ferrite (martensite) to form austenite. The second case is concerned with the $\gamma \rightarrow \alpha$ transformation, corresponding to ferrite formation from an initially austenitic phase. For each steel, the values of $\mathrm{T}_{\text {is }}, \mathrm{T}_{\max }$ and $\mathrm{T}_{\text {min }}$ were specifically chosen to span the entire range of the $a+\gamma$ region of the phase diagram. The temperature range $\Delta \mathrm{T}=\mathrm{T}_{\max }{ }^{-}$ $\mathrm{T}_{\text {min }}$, the heating and cooling rates, $\mathrm{HR}$ and CR respectively, as well as the period of the cycle $\tau$, were kept constant for the three steels, in order to ensure a maximum possible degree of correspondence between the cycles for the three materials. The above values are shown in Table 1. The equilibrium austenite and ferrite fractions, $f_{\gamma}$ and $f$ respectively, at $T_{\text {is }}$ were computed with Thermo-Calc [15] using the TCFE6 database for ferrous alloys and are also shown in Table 1.

Austenite and ferrite growth during the cyclic transformations was simulated by DICTRA [16] using the MOBFE2 mobility database Corresponding Author: Prof. Gregory Haidemenopoulos, University of Thessaly, Pedion Areos, 38500 Volos, Greece; E-mail: hgreg@mie.uth.gr

Citation: Sarafoglou PI, Tzini MIT, Haidemenopoulos GN (2015) Simulation of Cyclic Transformations in the Intercritical Range of a $5 \mathrm{Mn}$ Steel. Int J Metall Mater Eng 1: 104. doi: http://dx.doi.org/10.15344/2455-2372/2015/104

Copyright: (C) 2015 Sarafoglou et al. This is an open-access article distributed under the terms of the Creative Commons Attribution License, which permits unrestricted use, distribution, and reproduction in any medium, provided the original author and source are credited. 
Citation: Sarafoglou PI, Tzini MIT, Haidemenopoulos GN (2015) Simulation of Cyclic Transformations in the Intercritical Range of a 5Mn Steel. Int J Metall Mater Eng 1: 104. doi: http://dx.doi.org/10.15344/2455-2372/2015/104

Page 2 of 5
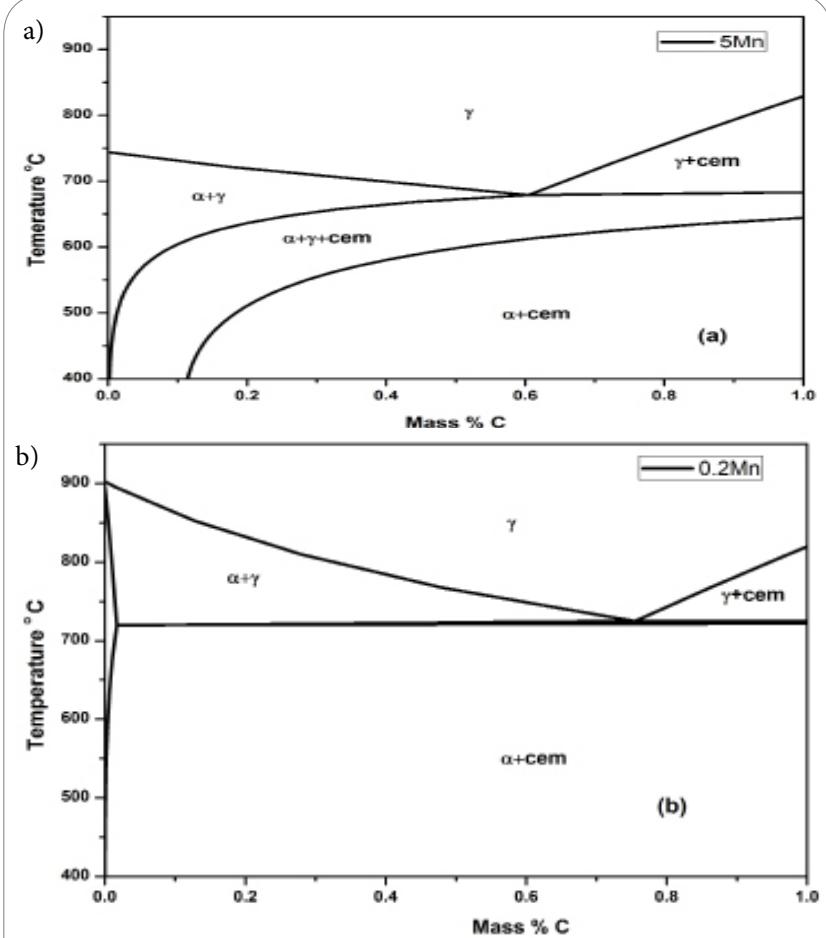

Figure 1: Isopleth sections of (a) Fe-5Mn, (b) Fe-0.2Mn steels.

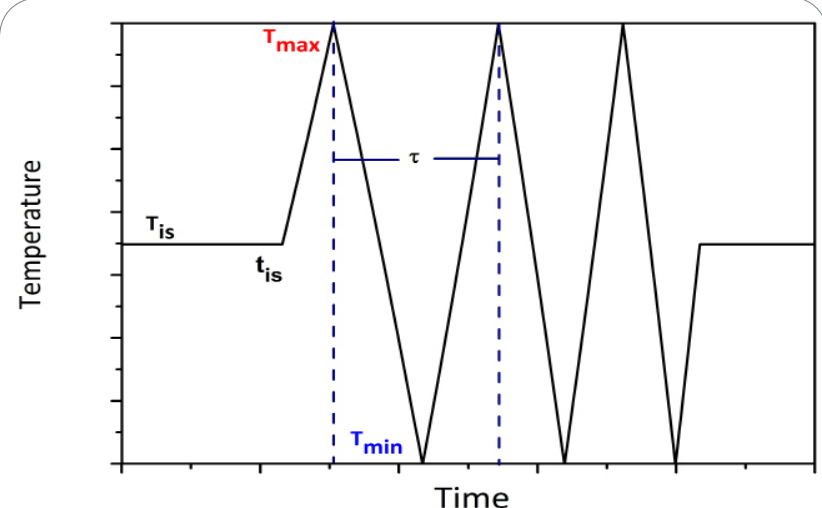

Figure 2: The temperature cycle considered in the simulations. $\mathrm{T}_{\text {is }}$ denotes the isothermal holding temperature, while $\mathrm{T}_{\max }$ and $\mathrm{T}_{\min }$ are the maximum and minimum temperatures respectively. The period of the cycle is $\tau$. attached to the left of the austenite region in Figure $3 b$ for the $\gamma \rightarrow a$ case. The regions were discretized with a linear grid consisting of 100 grid points. The initial compositions of austenite slice and ferrite in Figure $3 \mathrm{a}$ were taken equal to the nominal compositions of the alloy. The same holds for the ferrite slice and austenite region in Figure $3 \mathrm{~b}$.

Although the compositions in the two phases are identical, the respective activities are not. Diffusional fluxes are generated between the two phases as a response to the activity gradients. Zero flux boundary conditions (closed system) were considered at the upper and lower boundaries of the system. Throughout the simulation, local equilibrium (LE) conditions were imposed. The parameters monitored were (a) the position of the $\alpha / \gamma$ interface, normalized to the total region size, corresponding to the volume fractions $\mathrm{f}_{\gamma}$ and $\mathrm{f}_{\alpha}$ of austenite and ferrite for the $\alpha \rightarrow \gamma$ and $\gamma \rightarrow a$ cases respectively, and (b) the velocity of the $\alpha / \gamma$ interface $(\mathrm{VOI})$.

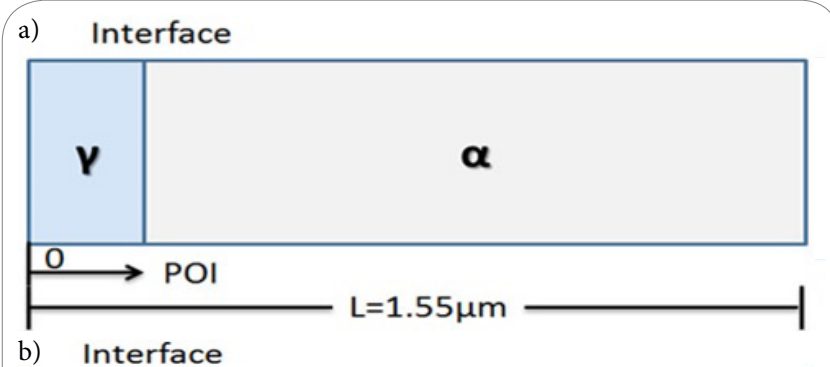

b) Interface

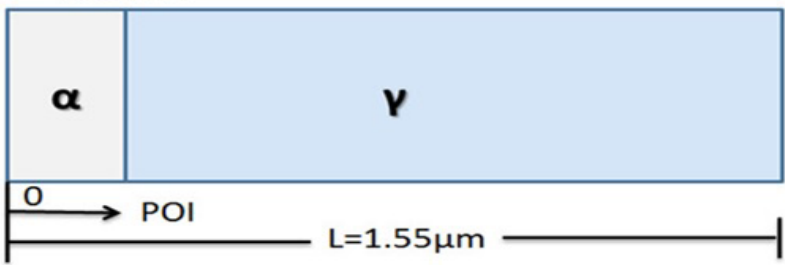

Figure 3: The representative cells employed in the DICTRA simulations of the cyclic transformations (a) cell for the $\alpha \rightarrow \gamma$ and (b) cell for the $\gamma \rightarrow a$ transformation.

\section{Results and Discussion}

\section{Fe-0.2C-5Mn steel}

The isothermal $\alpha \rightarrow \gamma$ and $\gamma \rightarrow \alpha$ transformations in the $\mathrm{Fe}-0.2 \mathrm{C}-5 \mathrm{Mn}$ steel are depicted in Figure 4 for three temperatures 640, 675 and $710^{\circ} \mathrm{C}$ corresponding to the $\mathrm{T}_{\min }, \mathrm{T}_{\mathrm{is}}$ and $\mathrm{T}_{\max }$ of the respective cyclic treatment. The $\alpha \rightarrow \gamma$ transformation exhibits the three-stage behavior discussed in $[18,19]$, i.e. non-partitioning local equilibrium (NPLE)

\begin{tabular}{|l|l|l|l|l|l|l|l|l|l|}
\hline $\begin{array}{l}\text { Chemical composition } \\
{[\mathrm{wt} \%]}\end{array}$ & $\begin{array}{l}\mathrm{A}_{1} \\
{\left[{ }^{\circ} \mathrm{C}\right]}\end{array}$ & $\begin{array}{l}\mathrm{A}_{2} \\
{\left[{ }^{\circ} \mathrm{C}\right]}\end{array}$ & $\begin{array}{l}\mathrm{T}_{\mathrm{is}} \\
{\left[{ }^{\circ} \mathrm{C}\right]}\end{array}$ & $\begin{array}{l}\mathrm{T}_{\min } \\
{\left[{ }^{\circ} \mathrm{C}\right]}\end{array}$ & $\begin{array}{l}\mathrm{T}_{\max } \\
{\left[{ }^{\circ} \mathrm{C}\right]}\end{array}$ & $\begin{array}{l}\Delta \mathrm{T} \\
{\left[{ }^{\circ} \mathrm{C}\right]}\end{array}$ & $\begin{array}{l}\mathrm{HR}-\mathrm{CR} \\
{\left[{ }^{\circ} / \mathrm{min}\right]}\end{array}$ & $\begin{array}{l}\tau \\
{[\mathrm{sec}]}\end{array}$ \\
\hline Fe-0.2c-5Mn & 634 & 716 & 675 & 640 & 710 & 70 & 10 & 840 & 0.394 \\
\hline Fe-0.2c-0.2Mn & 722 & 828 & 775 & 740 & 810 & 70 & 10 & 840 & 0.605 \\
\hline Fe-0.2c & 725 & 835 & 780 & 745 & 815 & 70 & 10 & 840 \\
\hline
\end{tabular}

Table 1: The characteristics of the thermal cycle for the three steels considered. $\mathrm{T}_{\mathrm{i}}$ is the isothermal holding temperature, $\mathrm{T}$ and $\mathrm{T}$ are the maximum and minimum temperatures respectively, $\mathrm{HR}$ and CR are the heating and cooling rates respectively, $\tau$ is the period of the cycle. The volume fractions of austenite and ferrite at $\mathrm{T}_{\text {is }}$ are $\mathrm{f}_{\gamma}$ and $\mathrm{f}_{\alpha}$ respectively.

for ferrous alloys. A single cell planar geometry was employed, shown in Figure 3 for the $\alpha \rightarrow \gamma$ and $\gamma \rightarrow \alpha$ cases. The total region size was taken equal to $1.55 \mu \mathrm{m}$ corresponding to one-half the measured ferrite-to-austenite mean distance (center-to-center) from ref. [17]. A thin austenite slice was attached to the left of the ferrite region in Figure 3a for the $a \rightarrow \gamma$ case. Correspondingly a thin ferrite slice was growth in stage I controlled by carbon diffusion in ferrite, partitioning local equilibrium (PLE) growth in stage II controlled by manganese diffusion in ferrite and PLE shrinkage of austenite in stage III controlled by manganese diffusion in austenite. Compared with the $\alpha \rightarrow \gamma$, the $\gamma \rightarrow \alpha$ transformation is much slower. Two specific times, $t_{s}$, were identified as the start of the cyclic transformations. In the first 
Citation: Sarafoglou PI, Tzini MIT, Haidemenopoulos GN (2015) Simulation of Cyclic Transformations in the Intercritical Range of a 5Mn Steel. Int J Metall Mater Eng 1: 104. doi: http://dx.doi.org/10.15344/2455-2372/2015/104

Page 3 of 5

case $\mathrm{t}=1 \times 10^{8} \mathrm{sec}$ after equilibrium volume fractions for both austenite and ferrite have been established in the isothermal transformation. In the second case, $t_{s}=2 \times 10^{3} \mathrm{sec}$, where the $\alpha \rightarrow \gamma$ transformation is evolving while the $\gamma \rightarrow a$ transformation is very sluggish. These times are depicted by dotted lines in Figure 4 .

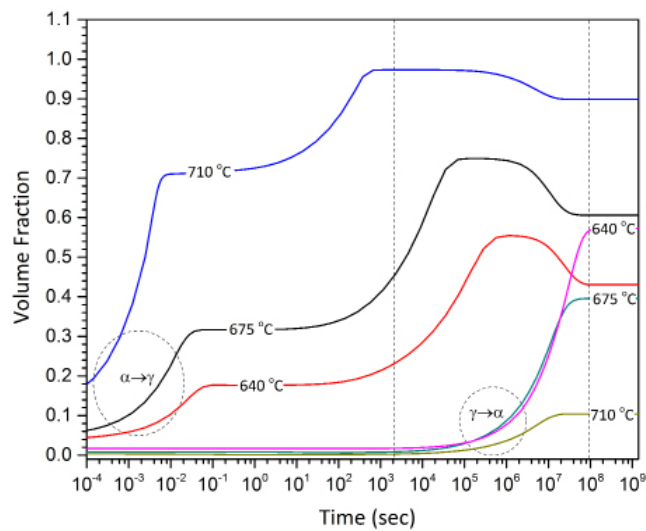

Figure 4: Isothermal $\alpha \rightarrow \gamma$ and $\gamma \rightarrow \alpha$ transformations in the Fe-0.2C-5Mn steel for 640,675 and $710^{\circ} \mathrm{C}$

The details of the inverse transformation are depicted in a magnified region in the second cycle of Figures $5 \mathrm{c}$ and $5 \mathrm{~d}$ in Figures $6 a$ and $6 b$ respectively for the $\alpha \rightarrow \gamma$ and the $\gamma \rightarrow a$ cases. Point $C$ on the volume fraction curve corresponds to the point of temperature change at $\mathrm{T}_{\text {max }}$ while point $\mathrm{D}$ corresponds to the change of interface direction at $\mathrm{VOI}=0$. Accordingly point $\mathrm{E}$ on the volume fraction curve corresponds to the point of temperature change at $\mathrm{T}_{\min }$ while point $\mathrm{F}$ corresponds to the change of interface direction at $\mathrm{VOI}=0$. The duration of the inverse transformation is larger at $\mathrm{T}_{\min }$, than the respective duration at $T_{\text {max }}$. The phase fraction formed during the inverse transformation is larger at the maximum temperature of the

cycle. A question, which arises, is whether there is a stagnant stage after the inverse transformation stage, observed in [14], where the transformation is sluggish with the temperature change. According to Figure 6 there is no absolute stagnant stage, i.e. a period where VOI $=0$. The interface is migrating continuously at low velocities even when it changes direction at $\mathrm{VOI}=0$. So a 'stagnant stage' characterized by very low interface velocity, is also observed in $5 \mathrm{Mn}$ steel.

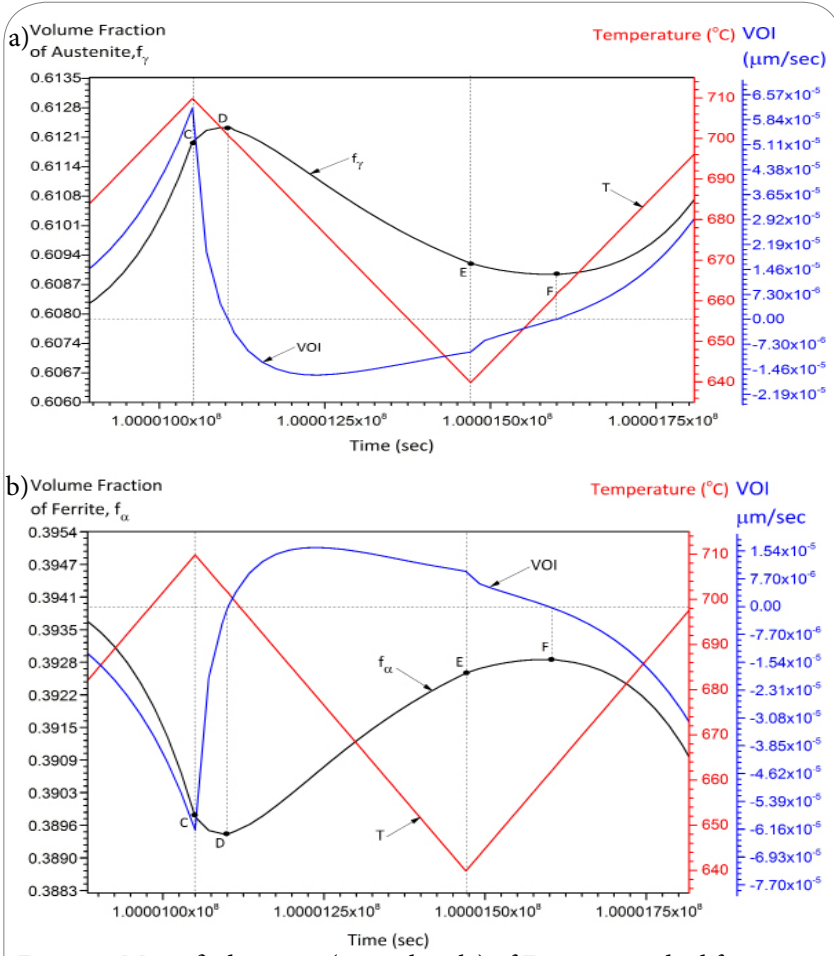

Figure 6: Magnified regions (second cycle) of Figure $5 \mathrm{c}$ and $5 \mathrm{~d}$ for $\alpha \rightarrow \gamma$ in (a) and $\gamma \rightarrow \alpha$ in (b) respectively, showing the inverse transformation.

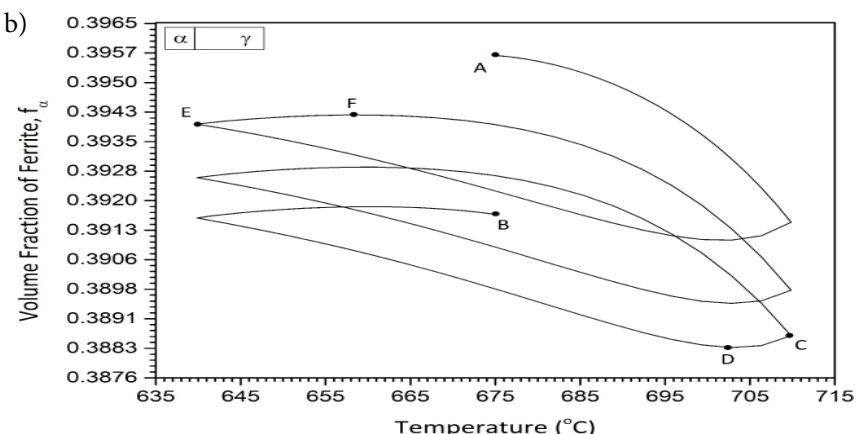

d) Volume Fraction Temperature $\left({ }^{\circ} \mathrm{C}\right)$ vol
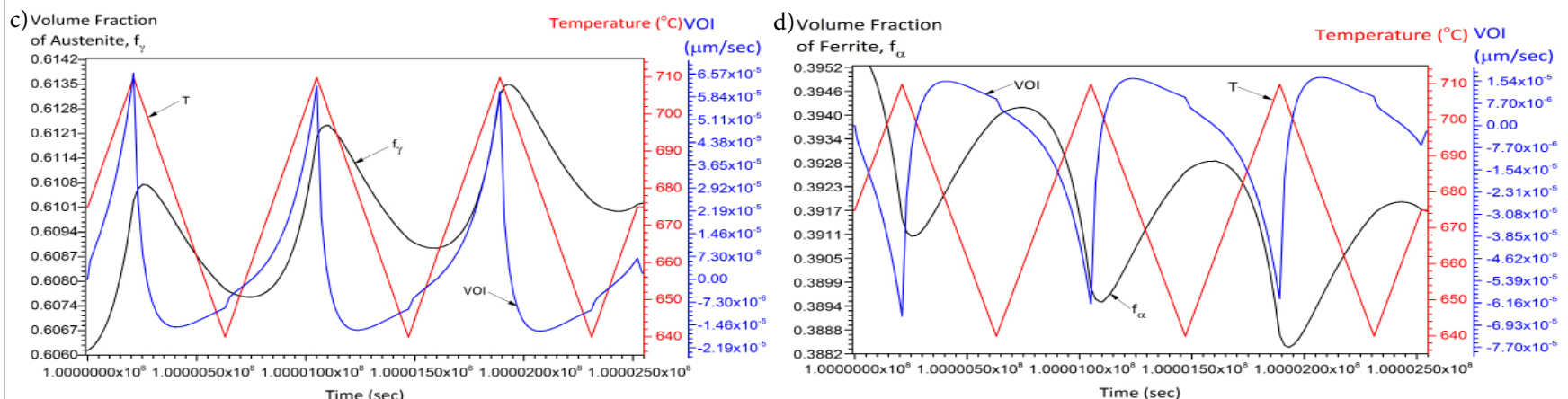

Figure 5: Cyclic transformations in Fe-0.2C-5Mn steel for $t_{s}=1 \times 10^{8}$ sec. (a) NPOI vs temperature for the $\alpha \rightarrow \gamma$, (b) NPOI vs temperature for the $\gamma \rightarrow a$, (c) NPOI and VOI vs time for the $\alpha \rightarrow \gamma$ and (d) NPOI, VOI vs time for the $\gamma \rightarrow \alpha$ transformations. 
Citation: Sarafoglou PI, Tzini MIT, Haidemenopoulos GN (2015) Simulation of Cyclic Transformations in the Intercritical Range of a 5Mn Steel. Int J Metall Mater Eng 1: 104. doi: http://dx.doi.org/10.15344/2455-2372/2015/104

Page 4 of 5

The cyclic transformation for $t_{s}=2 \times 10^{3}$ sec is depicted for the $\alpha \rightarrow \gamma$ case in Figure 7. The $\mathrm{f}_{\gamma}$ vs temperature is shown in Figure $7 \mathrm{a}$ and the $f_{\gamma}, T$ and VOI vs time are shown in Figure $7 b$.

Since in this case at $t_{\mathrm{s}}=2 \times 10^{3} \mathrm{sec}$, the $\gamma \rightarrow \alpha$ transformation during the isothermal treatment (Figure 4 ) is sluggish, the $\mathrm{f}_{\gamma}$ during cyclic transformation does not form hysteresis loops. On the contrary the $f_{\gamma}$ increases in each cycle, both in the heating and cooling part. In this case austenite forms by inverse transformation during the cooling part of the cycle.
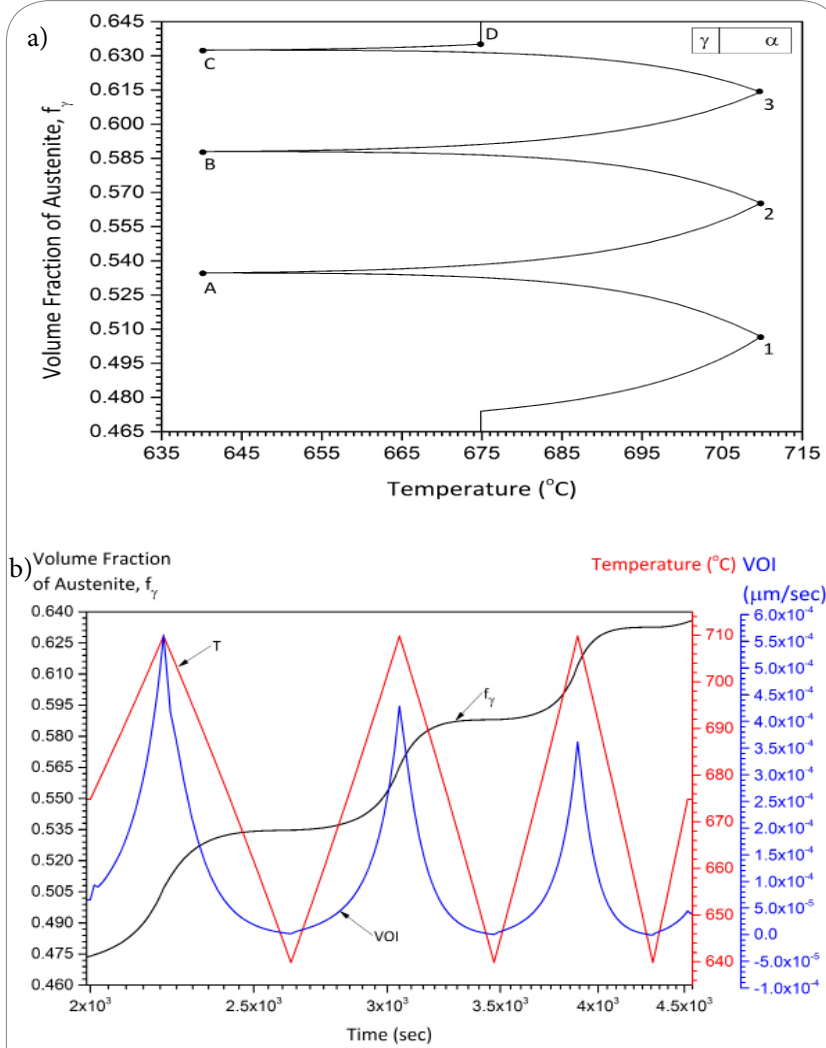

Figure 7: Cyclic transformations in Fe-0.2C-5Mn steel for $\mathrm{t}_{\mathrm{s}}=2 \times 10^{3} \mathrm{sec}$. (a) $\alpha \rightarrow \gamma$ vs temperature and (b) $\alpha \rightarrow \gamma$, VOI vs time.

\section{$\mathrm{Fe}-0.2 \mathrm{C}$ and $\mathrm{Fe}-0.2 \mathrm{C}-0.2 \mathrm{Mn}$ steels}

The isothermal transformations for the two steels are shown in Figure $8 \mathrm{a}$ and $8 \mathrm{~b}$. The kinetics of ferrite formation is much faster than in the Fe-0.2C-5Mn steel. The times ts indicating the start of the cyclic transformations are indicated by dotted lines.

The cyclic transformations (volume fraction vs temperature) for the two cases $\alpha \rightarrow \gamma$ and $\gamma \rightarrow a$ for the Fe-0.2C and Fe-0.2C-0.2Mn steels are shown in Figure $9 \mathrm{a}$ and $9 \mathrm{~b}$ for $\mathrm{t}_{\mathrm{s}}=100$ and $\mathrm{t}_{\mathrm{s}}=1 \times 10^{7} \mathrm{sec}$ respectively, corresponding to times where equilibrium fractions have been established in the respective isothermal curves. In the case of Fe- $0.2 \mathrm{C}$ steel containing no manganese, the transformation is reversible and no hysteresis loops are formed. This is due to the fast diffusion of carbon, establishing global equilibrium conditions quickly. In the case of the steel containing $0.2 \mathrm{Mn}$, a hysteresis loop forms during cycling transformation. The width of the loop, in the temperature axis, is smaller than the loops in the $5 \mathrm{Mn}$ steel. Obviously the partitioning of manganese during the cyclic transformations is the controlling factor for loop formation and inverse transformation stages. This issue is currently under investigation.
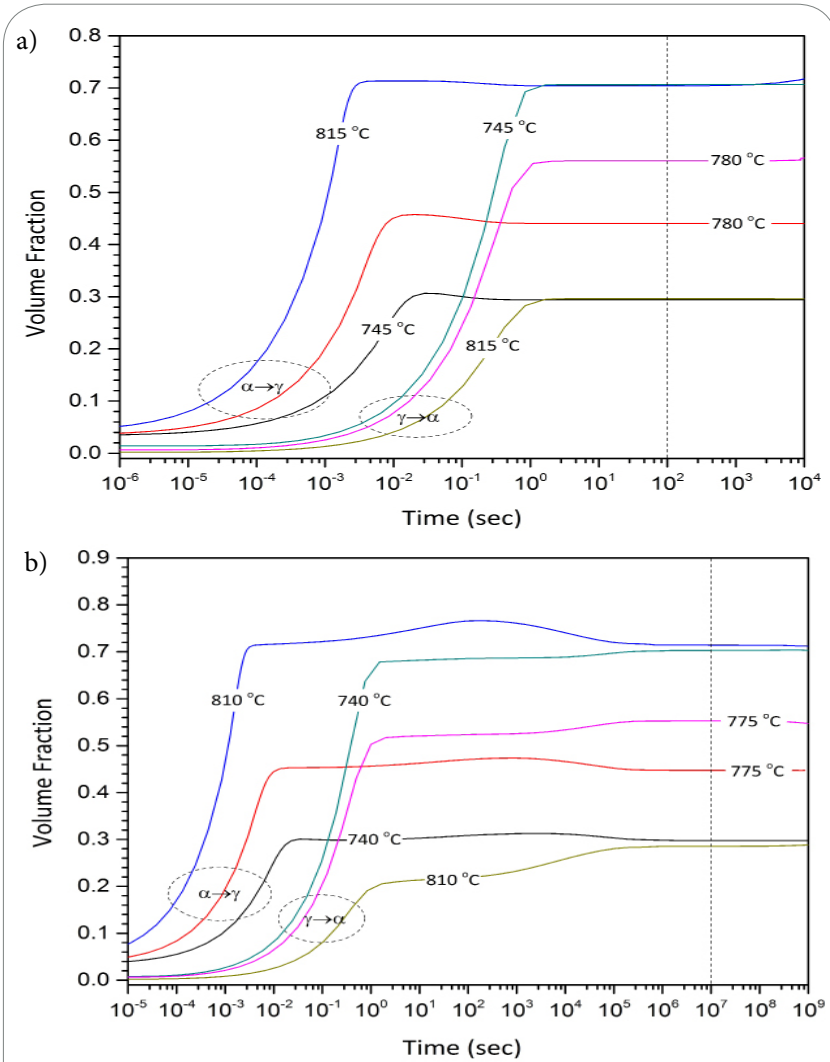

Figure 8: Isothermal transformation kinetics for (a) $\mathrm{Fe}-0.2 \mathrm{C}$ and (b) $\mathrm{Fe}$ $0.2 \mathrm{C}-0.2 \mathrm{Mn}$ steels.
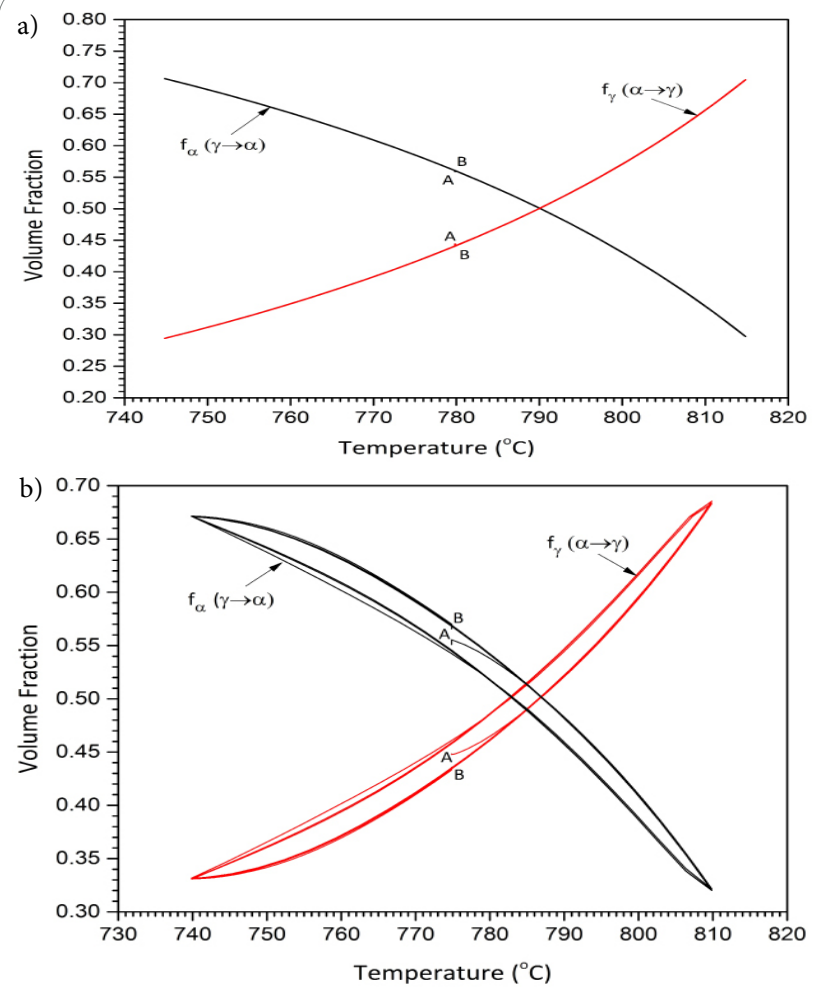

Figure 9: Cyclic transformations, volume fraction vs temperature for (a) Fe-0.2C and (b) Fe-0.2C-0.2Mn steels for both $a \rightarrow \gamma$ and $\gamma \rightarrow a$ transformations. 
Citation: Sarafoglou PI, Tzini MIT, Haidemenopoulos GN (2015) Simulation of Cyclic Transformations in the Intercritical Range of a 5Mn Steel. Int J Metall Mater Eng 1: 104. doi: http://dx.doi.org/10.15344/2455-2372/2015/104

Page 5 of 5

\section{Conclusion}

Cyclic phase transformations were simulated in Fe-0.2C-5Mn steel as well as in $\mathrm{Fe}-0.2 \mathrm{C}$ and $\mathrm{Fe}-0.2 \mathrm{C}-0.2 \mathrm{Mn}$ steels for comparison. From the results of the simulations the following conclusions can be drawn.

1. The cyclic behavior for a specific steel composition depends on the starting time of the cyclic treatment relative to the isothermal transformation curve.

2. When the cyclic treatment is performed after the equilibrium phase fractions during isothermal treatment have been established, hysteresis loops form in the $\mathrm{Fe}-0.2 \mathrm{C}-5 \mathrm{Mn}$ and $\mathrm{Fe}$ $0.2 \mathrm{C}-0.2 \mathrm{Mn}$ steels. The cyclic behavior is fully reversible for the $\mathrm{Fe}-0.2 \mathrm{C}$ steel.

3. The inverse transformation stage has been investigated for the Fe-0.2C-5Mn steel. The duration of the inverse transformation stage is larger at the minimum temperature of the cycle. The phase fraction formed during the inverse transformation is larger at the maximum temperature of the cycle.

4. In Fe-0.2C-5Mn steel, when the cyclic transformation takes place at a time before the final phase equilibrium in the isothermal curve, the transformation is characterized as inverse during the whole cooling part of the cycle.

5. A stagnant stage, where the transformation is very sluggish was observed during the cyclic transformations for the steels investigated.

\section{Competing Interests}

The authors declare that they have no competing interests exit.

\section{Author Contribution}

P.I Sarafoglou contributed to this work by carrying out simulations and supervising article content. Also contributed to the interpretation of the results.

M.I.T. Tzini contributed by carrying out simulations and by performing parametric analysis.

G.N. Haidemenopoulos contributed by designing the simulations, supervising the simulation work and interpreting the results.

\section{Acknowledgment}

The work has been conducted in the framework of the IKYDA 2014-2015 program "Design rules for 3rd generation advanced highstrength steels", which is a collaboration between UTH and RWTHAachen.

\section{References}

1. Matlock DK and Speer JG (2009) Third Generation of AHSS: Microstructure Design Concepts, in Microstructure and Texture in Steels, A Haldar, S Suwas, and D Bhattacharjee, Editors, Springer London.

2. Matlock DK, Speer J, De Moor E, Gibbs PJ (2012) JESTECH 15: 1-12.

3. Suh DW, Ryu JH, Joo MS, Yang HS, Lee K, Bhadeshia HKDH (2012) Medium-Alloy Manganese-Rich Transformation-Induced Plasticity Steels. Metall Mater Trans (A) 44: 286-293.

4. Lee S-J, Lee S and De Cooman BC (2011) Austenite stability of ultrafinegrained transformation-induced plasticity steel with $\mathrm{Mn}$ partitioning. Scr Mater 65: 225-228.

5. Speer JG, Assunção FCR, Matlock DK, and Edmonds DV (2005) The "quenching and partitioning" process: background and recent progress. Materials Research 8: 417-423.
6. Edmonds DV, He K, Rizzo FC, De Cooman BC, Matlock DK, et al. (2006) Quenching and partitioning martensite-A novel steel heat treatment. Mater Sci Eng (A) 438-440, 25-34.

7. Miller RL (1973) Metall Trans 3: 905-912.

8. Suh D-W, Park S-J, Lee T-H, Oh C-S, Kim S-J (2010) Influence of Al on microstructure and mechanical behavior of low carbon manganese transformation-induced plasticity steels. Metall Mater Trans (A) 41: 397 408.

9. Merwin MJ (2007) SAE Technical Paper, SAE, Warrendale, PA.

10. Huang H, Matsumura O, Furukawa T (1994) Retained austenite in low carbon, manganese steel after intercritical heat treatment. Mater Sci Technol 10: 621-626.

11. Cai ZH, Ding H, Xue $X$ and Xin QB (2013) Microstructural evolution and mechanical properties of hot-rolled $11 \%$ manganese TRIP steel. Mater Sci Eng (A) 560: 388-395.

12. Cai ZH, Ding H, Misra RDK, Kong H, Wu HY (2014) Unique impact of ferrite in influencing austenite stability and deformation behavior in a hot-rolled Fe-Mn-Al-C steel. Mater Sci Eng (A) 595: 86-91.

13. Chen H, Van der Zwaag S (2010) Application of the cyclic phase transformation concept for investigating growth kinetics of solid-state partitioning phase transformations. Comp Mater Sci 49: 801-813.

14. Chen H, Appolaire B, Van der Zwaag S (2011) Application of cyclic partial phase transformations for identifying kinetic transitions during solid-state phase transformations: Experiments and modeling. Acta Mater. 59: 67516760 .

15. Anderson JO, Helander T, Höglund L, Shi P, Sundman B (2002) ThermoCalc \& DICTRA, computational tools for materials science. Calphad 26 : 273-312.

16. Borgenstam A, Hoglund L, Agren J, Engstrom A (2000) Dictra a tool for simulation of Diffusional Transformations in Alloys. J Phase Equil 21: 269280.

17. Cai Z, Ding H, Misra RDK, Ying ZY (2015) Austenite stability and deformation behavior in a cold rolled transformation-induced plasticity steel with medium manganese content. Acta Mater 84: 229-236.

18. Wei R, Enomoto M, Hadian R, Zurob HS and Purdy GR (2013) Growth of austenite fromas-quenched martensite during intercritical annealing in an Fe-0.1C-3Mn-1.5Si alloy. Acta Mater 61: 697-707.

19. Nakada N, Mizutani K, Tsuchiyama T, Takaki S (2014) Difference in transformation behavior between ferrite and austenite formations in medium manganese steel. Acta Mater 65: 251-258. 